\title{
Os diferentes strategizings para o indicador TCAP do PPA 2008-2011: um estudo comparativo da visão da média gerência das três SPUs da região sul do Brasil
}

\begin{abstract}
The different strategizings for tcap indicator of multiannual plan - PPA 2008-2011: a comparative study of vision of middle managers of the three SPUS in southern region in Brazil
\end{abstract}

\author{
José Vladimir da Silva Brito ${ }^{1}$ \\ Vilmar Antônio Gonçalves Tondolo²
}

\section{Resumo}

Este estudo compara os Strategizings relativos aos resultados do indicador Taxa de Crescimento da Arrecadação Patrimonial do Plano Plurianual 2008-2011, na visão da média gerência das três superintendências do Patrimônio da União na Região Sul do Brasil. Por meio de um estudo de caso múltiplo, exploratório e com abordagem qualitativa, foi possível identificar aspectos que contribuem para o processo de desenvolvimento e implementação das estratégias governamentais pretendidas no PPA, tais como: modelo de gestão pública que comporte a adoção da abordagem da ECP; foco nas micro-atividades desenvolvidas pelos estrategistas; ênfase no processo interativo entre pessoas, ambiente, organização e a estratégia; planejamento estratégico mais próximo do nível operacional e acompanhado das estruturas necessárias à implementação.

Palavras-chave: Estratégia. Gerentes de Nível Médio. Administração Pública.

José Vladimir da Silva Brito. Mestre em Administração pela Universidade do Sul de Santa Catarina (UNISUL). Técnico de Nível Superior do Ministério do Planejamento, Orçamento e Gestão. Endereço: Praça XV de Novembro, 336, Centro - Florianópolis/SC, CEP 88.010-400. E-mail: vladbrito@hotmail.com. Telefone: (48) 9955-8892.

2 Vilmar Antônio Gonçalves Tondolo. Doutor em Administração pela Universidade do Vale do Rio dos Sinos (UNISINOS). Professor do Programa de Pós-Graduação em Administração da Universidade da Universidade de Caxias do Sul (UCS). E-mail: vtondolo@gmail.com 


\section{Abstract}

This study compares the Strategizings about the results of the Patrimonial Revenue Growth Rate indicator of the Multiannual Plan 2008-2011, in the view of the middle managers of the three superintendences of the Patrimônio da União in Southern Region of Brazil. Through a multiple case study, exploratory and qualitative approach, it was possible to identify aspects that contribute to the development process and implementation of government strategies intended on the PPA, such as: public management model that entails the adoption of the approach of ECP; focus in the micro-activities carried out by strategists; emphasis in the interactive process between people, environment, organization and strategy; strategic planning closer to the operational level and together with the structures necessary for implementation.

Keywords: Strategy. Middle Managers. Public Administration.

\section{Introdução}

O caso empírico pesquisado teve seu locus na Secretaria do Patrimônio da União (SPU), órgão subordinado ao Ministério do Planejamento, Orçamento e Gestão (MPOG) que é responsável pela administração do patrimônio imobiliário da União. A SPU, estruturada em unidade central (órgão central - OC) e unidades descentralizadas (superintendências), é composta por 27 unidades em todo o país (BRASIL, 2011). Em cada superintendência há um setor encarregado da arrecadação das receitas patrimoniais. Esses setores - as Divisões de Receitas Patrimoniais (DIREPs) - são corresponsáveis pelas metas de arrecadação patrimonial do órgão, em especial, concernente ao indicador do Plano Plurianual (PPA) 2008-2011: Taxa de Crescimento da Arrecadação Patrimonial (TCAP) (BRASIL, 2005).

Para o indicador TCAP desse PPA, estava estabelecida a meta de $146,29 \%$ de crescimento da arrecadação para 2011, com base no fechamento de 31.12.2006 (BRASIL, 2007). Por meio de consulta ao Sistema de Suporte à Decisão/Data Warehouse (SSD/DW) da SPU, na Tabela 1 estão apresentados os patamares atingidos pelas superintendências na Região Sul (em milhões de Reais). 
Tabela 1 - Patamares do indicador TCAP relativos às superintendências na Região Sul.

\begin{tabular}{l|c|c|c|c}
\hline Superintendência & $\begin{array}{c}\text { Referência 2006 } \\
\mathbf{( R \$ )}\end{array}$ & $\begin{array}{c}\text { Meta 2011 } \\
\mathbf{( R \$ )}\end{array}$ & $\begin{array}{c}\text { Consolidado } \\
\mathbf{( R \$ )}\end{array}$ & $\begin{array}{c}\text { Superação } \\
\mathbf{( \% )}\end{array}$ \\
\hline A & 10,21 & 14,93 & 17,44 & 116,81 \\
B & 16,05 & 23,47 & 45,28 & 192,93 \\
C & 2,77 & 4,05 & 5,77 & 142,47 \\
\hline
\end{tabular}

Fonte: Brasil (2011)

No intuito de analisar esses resultados sob a ótica estratégica, o escopo teórico adotado seguiu a corrente de pesquisadores europeus que priorizam o enfoque sociológico nos estudos sobre estratégia. Segundo essa corrente, a estratégia é algo que as pessoas da organização fazem (interação social) e não somente algo que a organização possui e impõe, podendo ser compreendida mediante as micro-atividades concernentes à construção da mesma (WHITTINGTON et al., 2007).

Sob esta concepção, o modelo teórico aplicado assume que o desenvolvimento de estratégias é o resultado da interseção entre os Praticantes, as Práticas e as Práxis, chamado Strategizing. De forma ampla, os Praticantes são os atores participantes e desenvolvedores do processo estratégico. As Práticas correspondem aos conceitos, às ideias e às tecnologias empregadas pelos estrategistas. Já as Práxis são relativas ao que os estrategistas fazem e os efeitos consequentes. Em especial, relativo aos Praticantes, este estudo enfatizou o papel desempenhado pela média gerência, uma vez que esta é corresponsável pela tradução da estratégia em pequenas seções, a fim de facilitar a implementação (PETERS; WATERMAN, 1988). Ademais, a ênfase se deve à média gerência conhecer os detalhes e as especificidades das ações necessárias à eficácia da gestão (NORDBLOM, 2006).

Dessa forma, a partir dos contextos empírico e teórico abordados, o problema de pesquisa foi definido em: como se desenvolveram os processos de Strategizing nas superintendências da Região Sul, na visão dos superintendentes e chefes das DIREPs, para o alcance dos resultados apresentados para o indicador TCAP do PPA 2008-2011? 
Por conseguinte, os objetivos centrais deste estudo foram analisar e comparar os Strategizings nas três superintendências da Região Sul, na visão dos superintendentes e chefes das DIREPs, em face dos resultados apresentados no indicador TCAP do PPA 2008-2011. Para tanto, desenvolveu-se um estudo de caso múltiplo, exploratório e com abordagem qualitativa. Estruturalmente, esse artigo se inicia com a parte introdutória, seguida do referencial teórico utilizado, da metodologia aplicada, da análise dos dados e resultados, finalizando com as considerações e as referências empregadas na investigação.

\section{Estratégia Como Prática (ECP)}

Em contraponto às abordagens de análise macro da estratégia que dão menor ênfase aos atores e às práticas cotidianas nas organizações, a ECP entende a estratégia como prática social. Nessa lógica, a compreensão da estratégia na organização não comporta exclusivamente conceitos ou definições, mas sim a compreensão do processo interativo entre ambiente, pessoas, organização e estratégia. Desse modo, à medida que o observador se aproxima da razão prática da estratégia, percebe a relevância das pessoas envoltas no processo, visto que a estratégia é planejada, desenvolvida e implementada pelas pessoas (WHITTINGTON, 2004).

Nesses termos, o entendimento da estratégia como prática social perpassa por admiti-la como uma atividade contextualizada e realizada socialmente. Também, é construída pelas ações e interações dos múltiplos atores envolvidos na prática estratégica, quer estejam na formulação, quer estejam na execução. Portanto, um estudo que adota a ECP focaliza interesse simultâneo nos Praticantes, nas Práticas e nas Práxis, que são os elementos da estratégia da organização, bem como suas mútuas interações. (JARZABKOWSKI, 2005; WHITTINGTON, 2006). Nesse sentido, é o resultado da interação entre essas três dimensões que irá determinar o Strategizing (FENTON; LANGLEY, 2011). A Figura 1 ilustra a influência mútua dessas três unidades de análise. 
Figura 1 - Os Praticantes, as Práticas e as Práxis na formação do Strategizing.

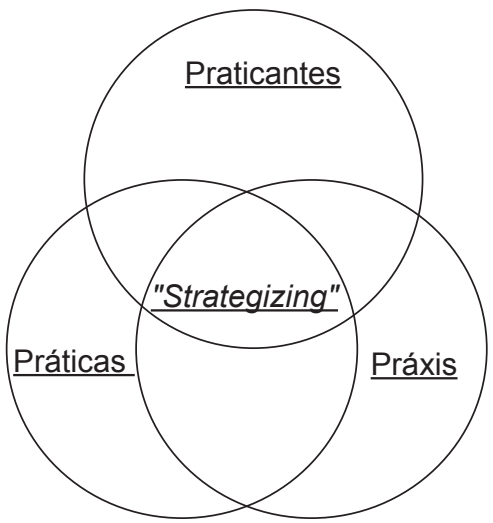

Fonte: Adaptado de Jarzabkowski, Balogun e Seidl, (2007).

Em linhas gerais, os Praticantes utilizam as Práticas para a produção e execução das Práxis; contudo o modelo que, à primeira vista, parece simples, apresenta-se complexo na medida de que se adentra nos meandros do seu contexto. Uma das razões é que a implementação da estratégia é uma fase crítica, pois não raro apresenta um expressivo percentual de insucesso e, assim, requer atenção dos Praticantes quanto às adaptações necessárias face às especificidades do contexto (CERTO et al., 2005; FREEDMAN, 2003; KAPLAN; NORTON, 2001). Outro motivo é que poucas ou nenhuma das estratégias são totalmente deliberadas, bem como são poucas as somente do tipo emergente. Dessa forma, os Praticantes - os estrategistas - só são eficazes se retrabalham as estratégias, adaptando-as às condições contextuais; se antecipam ao que pode ocorrer e se reagem apropriadamente frente aos eventos inesperados (MINTZBERG; AHLSTRAND; LAMPEL, 2000).

Portanto, a implementação exige dos Praticantes a habilidade de coordenar um amplo escopo de fatores para transformar intenções estratégicas em ação (HAMBRICK; CANELLA, 1989; HREBINIAK; JOYCE, 2005; SHAH, 2005). Atuar nesse contexto explica a tendência dos Praticantes em adotar Práticas estratégicas já consolidadas nas 
organizações, pois visam garantir a legitimidade e, com isso, minimizar o risco de ceticismo e críticas (SEIDL, 2003). Em vista disso, a estratégia se constitui em algo que os Praticantes "fazem" e não que as organizações "têm" (WHITTINGTON, 2003). Eles fazem uso das Práticas que prevalecem e permanecem por meio da adaptação, combinação e coordenação frente às necessidades de uso. Portanto, essas Práticas "contextualizadas", surgidas intencionalmente ou não, institucionalizamse com a colaboração dos Praticantes em novas Práticas resultantes (JARZABKOWSKI; BALOGUN; SEIDL, 2007).

Por definição, as Práticas correspondem às rotinas de comportamento compartilhadas e, nesse sentido, também são elencadas as normas, os procedimentos e as tradições concernentes ao agir, ao pensar e ao utilizar "coisas", no sentido amplo (WHITTINGTON, 2006). Como em cada oportunidade de aplicação dessas Práticas, invariavelmente o Praticante estará criando novas Práticas - porque sempre será preciso adaptá-las ao contexto pontual - essas, em essência, são reducionistas. Isso significa que a Prática estratégica mapeia a complexidade da organização em modelos cognitivamente compreensíveis, por meio dos quais é possível à organização implantar suas ações (SEIDL, 2003).

Tais ações, que compõem as Práxis, são os fluxos de atividades socialmente contextualizadas de forma ampla, que afetam de forma significativa o direcionamento e a sobrevivência da organização ou do setor ao qual fazem parte. Além disso, abragem as interligações entre as instituições estabelecidas e as ações dos indivíduos e grupos, mesmo que fisicamente distantes (JARZABKOWSKI; BALOGUN; SEIDL 2007). Em outras palavras, as Práxis representam o real trabalho dos Praticantes, ou seja, a forma como eles modificam, replicam e utilizam as Práticas da estratégia. (WHITTINGTON, 2006). Haja vista a ênfase na prática social, o foco do interesse converge para as micro-atividades desempenhadas pelos indivíduos, pois, mesmo que detentores em potencial de objetivos e interesses individuais divergentes, estes estão em interação contínua, compartilham significados e concorrem para 
que a estratégia se traduza nos resultados pretendidos. Ademais, três razões embasam a valorização do aspecto micro no desenvolvimento estratégico:

1) A negligência com as micro-atividades repercute em resultados organizacionais aquém do esperado;

2) Pesquisadores afirmam que os elementos que dão origem à vantagem competitiva se encontram nos detalhes e não nos aspectos macros e óbvios;

3) Os responsáveis, de fato, pela execução das atividades estratégicas são os gestores do nível micro (WHITTINGTON; JOHNSON; MELIN, 2004).

\section{Plano Plurianual}

O PPA foi instituído de forma inovadora pela Constituição Federal de 1988 (CF/88) e surgiu em um cenário onde se almejava tanto um reequilíbrio entre os poderes legislativo, judiciário e executivo, quanto um novo direcionamento relativo aos aspectos fiscais e de controle sobre a atuação do Executivo (PARES; VALLE, 2006). Entre outros objetivos, o PPA se propôs a harmonizar a execução dos orçamentos anuais aos objetivos de longo prazo, mediante o planejamento das políticas públicas em um horizonte quadrienal; portanto os constituintes entenderam o planejamento como uma função indispensável ao Estado e não uma escolha do governante (PAULO, 2010). Nesses termos, conforme ilustra a Figura 2, o PPA pode ser compreendido como instrumento mediador dos investimentos estratégicos que aproxima os objetivos indicativos de Estado (longo prazo), as políticas de governo (médio prazo) e os gastos orçamentários anuais (curto prazo). 
Figura 2 - A relação do PPA com os objetivos indicativos de Estado, as políticas de Governo, e os gastos orçamentários anuais.

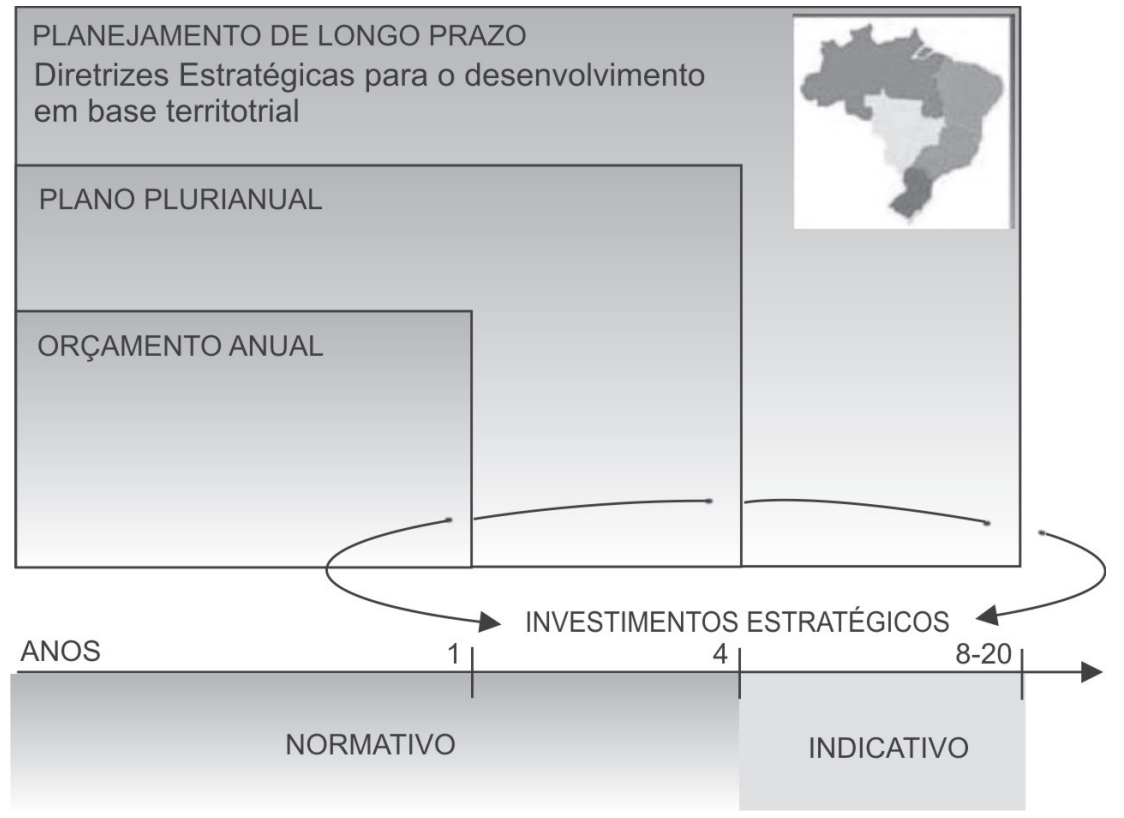

Fonte: BRASIL, 2007.

Entretanto, outros planos com perfil estratégico foram desenvolvidos em paralelo ao PPA 2008-2011: a Agenda Social, o Plano de Desenvolvimento da Educação e o Programa de Aceleração do Crescimento (BRASIL, 2007). Essas outras formas de apresentação dos objetivos e prioridades do Governo, presentes no PPA apenas em respeito ao procedimento burocrático, vêm reforçar a ideia de que o PPA represente uma peça meramente burocrática, cuja função maior é servir de instrumento de transparência aos órgãos de controle interno e externo do Governo Federal.

Reconhecer o aspecto estratégico do PPA encontra resistência, tanto entre planejadores e tomadores de decisão, quanto entre parlamentares, estudiosos e especialistas (PAULO, 2010). Entretanto, mesmo que esse modelo resulte em poucos avanços no sentido de se 
garantir a melhoria da eficiência e efetividade dos gastos públicos, é constatável que o desenho do PPA 2008-2011 apresenta aspectos do modelo de orçamento por resultados ou desempenho (CAVALCANTE, 2007).

Realizadas essas considerações, este estudo admitiu o PPA como plano estratégico para consecução dos objetivos pretendidos pelo Governo e, por conseguinte, assumiu que foi baseado nas orientações contidas em suas diretrizes que foram definidas as ações implementadas no nível tático-operacional.

\section{Metodologia}

Para atingir o objetivo proposto, foi desenvolvido um estudo de caso exploratório com abordagem qualitativa. Exploratório, porque visa investigar acontecimentos contemporâneos, pretende obter novos conhecimentos, questiona e analisa os fenômenos sob uma perspectiva nova(MARSHALL; ROSSMAN, 1995; SAUNDERS; LEWIS; THORNHILL, 2009). Qualitativa, porque se justifica como mais adequada ao propósito interpretativo e contextual do Strategyzing (SPEE; JARZABKOWSKI, 2011).

A opção pelo estudo de caso múltiplo como estratégia de pesquisa se deu devido à busca para compreender fenômenos sociais complexos e atuais (YIN, 2005) e, adicionalmente, porque foi realizada em três organizações distintas - as três superintendências na Região Sul. A coleta de dados primários nessas superintendências foi realizada mediante entrevistas semiestruturadas, pois são as técnicas indicadas em uma pesquisa exploratória (MARSHALL; ROSSMAN, 1995) e por serem usualmente utilizadas na pesquisa qualitativa (REMENYI et al., 2005). Após a validação do pré-teste, as entrevistas, no total de seis, foram realizadas uma única vez com cada entrevistado, entre outubro e novembro de 2011, com os ocupantes dos cargos de superintendentes e chefes das DIREPs, uma vez que correspondem à média gerência do órgão que responde pelo indicador TCAP. O roteiro das entrevistas foi estruturado em 14 questões dividas em blocos que corresponderam aos 
Praticantes, às Práticas e às Práxis, para compreensão dos Strategizings. Sobre a transcrição das entrevistas foi aplicada a análise de conteúdo, a fim de captar os pontos de vista subjetivos (FLICK, 2009; BARDIN, 2006; CHIZZOTTI, 2006; MINAYO, 2001). De forma resumida, a Tabela 2 apresenta os dados quantitativos das pesquisas realizadas.

Tabela 2 - Perfis quantitativos das pesquisas.

\begin{tabular}{l|c}
\hline Perfil quantitativo das entrevistas & 6 \\
\hline$N^{\circ}$ de entrevistados & $\mathbf{4 4}$ minutos \\
Duração da entrevista - Chefe 1 & $\mathbf{6 3}$ minutos \\
Duração da entrevista - Chefe 2 & $\mathbf{8 1}$ minutos \\
Duração da entrevista - Chefe 3 & $\mathbf{2 8}$ minutos \\
Duração da entrevista - Superintendente X & $\mathbf{4 6}$ minutos \\
Duração da entrevista - Superintendente Y & $\mathbf{5 1}$ minutos \\
Duração da entrevista - Superintendente Z & minutos) \\
Duração total das entrevistas & 37.483 \\
\hline Quantidade de palavras nas transcrições & \\
\hline Perfil quantitativo da pesquisa documental & $N^{\circ}$ páginas analisadas \\
\hline Documentos & 61 \\
\hline Relatório de Gestão 2010 da Superintendência A & 78 \\
Relatório de Gestão 2010 da Superintendência B & 51 \\
Relatório de Gestão 2010 da Superintendência C & 103 \\
Relatório de Gestão 2008 da SPU & 127 \\
Relatório de Gestão 2009 da SPU & 174 \\
Relatório de Gestão 2010 da SPU & 594 \\
\hline Total &
\end{tabular}

Adicionalmente, houve a coleta de dados secundários, que se deu por análise de documentos como uma estratégia complementar às entrevistas (FLICK, 2009). Inicialmente, foram pesquisados os relatórios de gestão de 2010 das superintendências; todavia, face ao indicativo de sobreposição de instrumentos de gestão que concorrentemente utilizavam a arrecadação patrimonial como indicador, a pesquisa foi estendida aos relatórios de gestão de 2008 e 2009. 


\section{Análise dos dados}

A seguir são apresentados os resultados obtidos por meio da análise aplicada às entrevistas, como dados primários; e, aos documentos, como dados secundários.

\subsection{Análise das entrevistas}

A aplicação da análise de conteúdo sobre os 505 temas identificados na transcrição das entrevistas revelou as respostas mais enfáticas na visão da média gerência das superintendências. No intuito de contribuir para o anonimato dos entrevistados, as superintendências foram codificadas como superintendência A (SPU/A), superintendência $B(S P U / B)$ e superintendência C (SPU/C).

Relativo ao primeiro bloco, sobre os Praticantes, a primeira pergunta foi relativa ao perfil dos entrevistados e seu papel no processo estratégico. Foi verificado que todos têm, no mínimo, formação acadêmica superior e já tinham experiência no setor público antes de assumirem seus encargos nas superintendências.

A segunda pergunta inquiriu sobre a visão dos Praticantes concernente à arrecadação patrimonial, no que tange à contribuição da mesma para o alcance dos objetivos do PPA. Os temas identificados foram os seguintes:

SPU/A: Pode contribuir para os programas sociais.

SPU/B: Não é importante para os objetivos do PPA.

SPU/C: Tem valor em si mesma; é importante para os objetivos do PPA; e contribui positivamente para o órgão.

Foi interessante perceber que a SPU/B não reconhece a contribuição da arrecadação patrimonial para o alcance dos objetivos do PPA, levando-se em conta que esta apresentou a maior superação no período (192,93 \%). Ademais, frente às opiniões desencontradas, transpareceu que a média gerência não observou correspondência entre os objetivos do PPA e a arrecadação como indicador contribuinte ao PPA, 
confirmando a afirmação de Cavalcante (2007) sobre os indicadores serem, por consequência, ignorados no decorrer do Plano. Ademais, reforça a compreensão de Paulo (2010) de que o PPA se constitui em peça meramente burocrática para os planejadores e tomadores de decisão. Essa contradição ficou bem expressa na declaração de um entrevistado dessa superintendência:

A arrecadação hoje dentro do Patrimônio da União, ela tá - eu vou usar um termo até pesado - disfuncional. Qual é o motivo de a gente tá tentando arrecadar, se o próprio mandatário não consegue ver esse pouco que a gente arrecada como fundamental?

A seguir, foi solicitado aos entrevistados que definissem o que é estratégia. O objetivo foi compreender o enfoque estratégico da média gerência. Os temas reconhecidos, dois a dois, foram:

SPU/A: Atingir os objetivos mediante os recursos disponiveis (concepção analítica); e atingir os objetivos mediante aumento da eficiência (concepção adaptativa).

SPU/B: Atingir os objetivos mediante o planejamento executivo (concepção prescritiva); e atingir os objetivos mediante escolhas contextualizadas (concepção incrementalista).

SPU/C: Atingir os objetivos mediante o conjunto de meios elaborados (concepção analítica); e atingir os objetivos mediante o planejamento executivo (concepção prescritiva).

A pergunta seguinte solicitou a visão dos Praticantes concernente à implementação das estratégias. Os temas destacados foram:

SPU/A: Ter a estrutura adequada é um fator positivo.

SPU/B: A arrogância da alta gerência é um aspecto negativo.

SPU/C: O planejamento executivo é um fator favorável.

Conforme defendido por Jarzabkowski, Balogun e Seidl (2007), observou-se que as práticas que prevalecem e estão em uso devem-se à adaptação, à combinação e à coordenação, bem como às necessidades 
em curso, visto almejarem a eficácia de suas ações ao combinar as estratégias, seja antevendo, reagindo aos eventos ou se adaptando às condições existentes (MINTZBERG; AHLSTRAND; LAMPEL, 2000). Um trecho de uma entrevista na SPU/C elencou de forma abrangente a importância do planejamento naquela superintendência:

Primeira coisa é fazer um levantamento do que já tem. De onde é que nós vamos partir pra chegar nesse objetivo. O que nós temos construído, o que nós temos de história disso. O que já aconteceu a respeito do assunto, quais as informações que nós já temos catalogadas. Quem eu tenho à disposição para trabalhar com isso. O caminho que nós vamos ter que trilhar para ter esse objetivo.

Na sequência, os Praticantes foram questionados a respeito do processo comunicativo. Seguem os temas identificados:

SPU/A: Inexiste interação, a despeito de ocorrer o retorno topdown.

SPU/B: Inexiste interação.

SPU/C: Há transparência nos procedimentos.

Observou-se que os entrevistados procuraram contribuir com os seus conhecimentos detalhados das atividades operacionais, dessa forma, colaborando para a estratégia se tornar realizável, empenhandose junto aos atores envolvidos, conforme defende Nichol (1992); todavia, no caso específico, junto à alta gerência, os praticantes não têm tido sucesso nesse propósito. A queixa em comum das SPU/A e a SPU/B ficou bem clara na declaração de um entrevistado da primeira:

Hoje, já tem melhorado isso aí, em razão da própria busca mesmo pela regional. A gente já tem lutado, brigado por isso, tem melhorado. O órgão central tem nos ouvido mais, mas ainda não está, ainda, do jeito que a regional realmente necessita. Não é nem que a regional necessita, mas os nossos usuários, nossos contribuintes, que necessitam de uma resposta mais urgente nossa, e às vezes a gente não tem, e a gente 
tem que recorrer justamente ao nosso órgão central, que às vezes deixa a desejar.

A pergunta final sobre os Praticantes indagou sobre a visão relativa ao processo decisório. Os temas enfatizados foram os seguintes:

SPU/A: É necessária a descentralização da tomada de decisões.

SPU/B: São desconsideradas as restrições.

SPU/C: As decisões são do tipo top-down, um aspecto negativo.

As evidências levam a crer que as estratégias são, de certa forma, restritas à dimensão prática-avaliativa que, de acordo com os estudos de Jarzabkowski e Wilson (2006), são assim devido às contingências contextuais e aos aspectos de ambiguidade, conflito e incerteza. Um trecho da entrevista realizada na SPU/B ressalta essas dificuldades em comum citadas pela média gerência:

O chão de fábrica espera de você respostas prontas, rápidas, onde você demonstre segurança. E muitas vezes você fica vendido, porque você não tem essa resposta pronta, quando você busca você não encontra, inexiste manualização, as rotinas são arcaicas, a estrutura é extremamente deficiente, o regimento está ultrapassado, não espelha a estrutura e nem os procedimentos da forma como são executados. Então, na realidade, você tá fabricando a cada momento soluções.

O bloco sobre as Práticas foi iniciado solicitando à média gerência que elencasse as Práticas que mais contribuem para a arrecadação patrimonial. Nos temas identificados, ficou notória a importância da atualização cadastral:

SPU/A: A atualização do cadastro.

SPU/B: A atualização do cadastro.

SPU/C: A atualização do cadastro, a realização de transferências e a notificação direta. 
Esse rol de Práticas atende a um dos questionamentos propostos por Jarzabkowski, Balogun e Seidl (2007) para uma pesquisa em ECP e, por conseguinte, serve para explicitar o nível de conhecimento técnico dos entrevistados.

A pergunta seguinte inquiriu os Praticantes sobre os aspectos implementativos quando as Práticas são postas em execução. Seguem os temas destacados:

SPU/A: Se faz necessário o retorno down-top; e falhas ocorrem por falta de recursos.

SPU/B: É necessário o exercício do controle, bem como o incrementalismo e a inexistência de interação afeta de forma negativa.

SPU/C: É necessário o incrementalismo.

Observou-se no incrementalismo praticado que os praticantes traduzem a estratégia em pequenas partes, a fim de facilitar a implementação - como Peters e Waterman Junior (1988) defendem. Adicionalmente, as críticas destacadas comprovaram o entendimento de Nordblom (2006), para quem o permanente contato com as atividades implementadoras possibilita aos Praticantes conhecerem as especificidades e os detalhes das ações necessárias à eficácia da gestão, objetivando as metas estabelecidas.

Um entrevistado na SPU/C exemplificou em seu discurso as dificuldades enfrentadas:

As transferências que acabam ocorrendo em alguns municípios, sem autorização da União, é outra alteração da Prática, que na verdade já não é mais nem uma exceção, porque já se constitui a regra, porque são tantas, apesar de providências tenham sido tomadas a respeito, inclusive judiciais. Aparentemente, daqui pra frente, as coisas mudem, não se resolvam totalmente, mas pelo menos mudem. Começa a se criar uma cultura mais séria em relação à legislação, mas nós temos um passivo, um passado todo, de transferências feitas sem autorização que precisam ser regularizadas. Então, isso 
foge à nossa prática e a gente precisa adequar a nossa estratégia a essa realidade.

Questionados sobre os aspectos contextuais como as Práticas afetam as atividades estratégicas cotidianas nas superintendências, a média gerência enfatizou os seguintes temas:

SPU/A: São fatores negativos: a ausência de tempo hábil e desconsiderar as restrições.

SPU/B: Ocorrem falhas por falta de estrutura.

SPU/C: A ausência de tempo hábil afeta negativamente.

Estas respostas relacionaram os diversos aspectos contextuais que caracterizaram a dinâmica do Strategizing desenvolvido nas SPUs, que, conforme Johnson, Melin e Whittington (2003), sinalizam a necessidade de aprofundamento nos âmbitos micro da estratégia, tanto para compreender as ligações relativas ao desempenho, quanto para o direcionamento das ações gerenciais.

A ênfase nos fatores limitantes como tempo hábil e as restrições estruturais está exemplificada na declaração obtida na SPU/C:

Quando são práticas que não podem ser alteradas em relação ao prazo, por exemplo, a data limite para a grande emissão, muitas vezes, temos que parar com todo o outro trabalho para atender àquela demanda, tendo em vista o número limitado de servidores. Outras vezes, quando se pode minimamente alterar a ordem, estabelecemos prioridades para conseguir atender mesmo que destoe um pouco da ordem estabelecida pelo órgão central.

No caso de precisarem incrementar a arrecadação patrimonial, foi solicitado aos Praticantes que descrevessem o modelo institucional necessário. Os temas mais destacados foram:

SPU/A: É preciso estruturar do órgão.

SPU/B: São necessárias comissões mistas entre os setores e é preciso a atualização do cadastro. 
SPU/C: É preciso estruturar do órgão e a atualização do cadastro.

Esses modelos evidenciaram a prática estratégica em sua forma mentalizada pelos entrevistados, haja vista, como defende Seidl (2003), que o mapeamento da complexidade do ambiente em modelos cognitivamente compreensíveis é a forma que possibilita à organização adotar suas ações. Ademais, trouxe à luz, conforme a definição de Floyd e Wooldridge (1992), que os Praticantes são meros implementadores da estratégia deliberada, porque ajustam, revisam, implementam, adequam e motivam a equipe visando aos fins pretendidos.

Um trecho de uma entrevista na SPU/A elenca os principais aspectos do modelo pensado pela média gerência:

Outra questão é a União hoje ter muitos imóveis que são da União e não são conhecidos pela União. Nós temos hoje, no Brasil, a faixa de 600 mil imóveis cadastrados, mas nós temos um potencial para chegar a mais de um milhão de imóveis. Isso, pela deficiência das superintendências em termos de estrutura, em termos de qualificação dos servidores. Então, uma série de coisas que nos leva a não incrementar a nossa arrecadação, pelas nossas limitações, entende? Então, se nós pegássemos e fizéssemos um trabalho de recadastramento a nível Brasil, eu tenho certeza que a nossa arrecadação iria sofrer bastante aumento.

No fechamento das perguntas sobre as Práticas, foi requerido aos entrevistados que se pronunciassem sobre a cultura organizacional, em especial, quando novas Práticas se deparam com outras Práticas estratégicas já estabelecidas nos ambientes. Os temas identificados foram as seguintes:

SPU/A: É preciso flexibilidade, rapidez e priorização para a adaptação.

SPU/B: É necessária uma gestão middle-up-down, bem como o exercício do controle.

SPU/C: É necessário o engajamento do nível operacional. 
Esses resultados corroboraram as pesquisas de Certo e Peter (2005), Freedman (2003) e Kaplan e Norton (2001), onde afirmam que em um momento de implementação e mudança, é demandada atenção quanto às adaptações necessárias, haja vista as especificidades contextuais. Ademais, tanto a gestão middle-up-down, a escolha racional-contextual, quanto a flexibilidade, nada mais são que aspectos destacados por Mintzberg, Ahlstrand e Lampel (2000), no que concerne ao incrementalismo cíclico entre a formulação e a implementação.

Um entrevistado na SPU/C exemplificou esse momento em sua declaração:

Então, tem que ser feito um trabalho anterior para que o impacto não seja desorganizado. Tem que seguir e procurar adaptar as pessoas a essa nova realidade, e cabe a mim esse papel. Então, com as pessoas que trabalham diretamente comigo, eu procuro fazer dessa forma. Normalmente, é o que acontece também em nível de superintendência. Nós ficamos sabendo das alterações e então temos tempo para nos adaptar a essa nova realidade. Claro que sempre existe alguma dificuldade na hora de colocar em prática... "- Ah, me esqueci que não podia"... E precisa ser refeito, mas nada que se constitua um grande problema... São exceções.

Concernente às Práxis, a pergunta inicial questionou os Praticantes sobre por que as coisas são feitas do jeito que são. Os temas mais destacados foram:

SPU/A: Devido ao engajamento do nível operacional.

SPU/B: Porque há uma cultura de descompromisso com a eficiência.

SPU/C: Devido à estrutura determinística.

O rol de Práxis elencado pelos entrevistados representou o que Whittington (2003) conceitua como o real trabalho. Do mesmo modo que o questionamento sobre como as Práticas afetavam as atividades estratégicas cotidianas nas superintendências, nesta pergunta, a média 
gerência expôs, sob sua ótica, essas mesmas práticas já adaptadas, estabelecidas e contextualizadas conforme a dinâmica do Strategizing em curso.

Uma declaração obtida na SPU/B ilustra a visão enfatizada naquela superintendência:

Bom, primeiro [quero] dizer que há uma cultura ainda arraigada do serviço público, de um serviço que necessariamente não precisa ser eficiente. Uma cultura que se traz de muito tempo. Segundo, a característica do Patrimônio da União é muito ainda [...] cartorial, e essa característica cartorial... Foi justamente nessa área do serviço público que mais conservadorismo se teve, [quanto] à eficiência do trabalho. Segundo a questão, claro, do jeito como se faz [...]. Outra questão: a legislação também não nos permite ter muitas formas outras, a não ser as que a legislação coloca. Terceiro, a disponibilidade de pessoal que você tem, realmente, às vezes não te permite fazer de outra forma, que poderia ser melhor.

A pergunta, na sequência, buscou entender os aspectos institucionais das Práxis; a relação entre a forma local de fazer as coisas e a superintendência como instituição. A média gerência destacou os seguintes temas:

SPU/A: A autonomia é somente operativa; uma forte interação com o órgão central afeta positivamente e as falhas no planejamento estratégico afetam negativamente.

SPU/B: As falhas no planejamento estratégico afetam negativamente.

SPU/C: Os encontros regionais afetam de forma positiva.

Esse questionamento captou como os indivíduos agiram em face da instituição, bem como observaram e contribuíram para a institucionalização das ações estratégicas (JARZABKOWSKI; BALOGUN; SEIDL, 2007). Desse modo, em conformidade com 
os estudos de Currie, Procte e Orne (1999), evidenciou-se que os Praticantes não tinham posse do empowerment necessário à tomada de decisões estratégicas contextuais e, portanto, restando o campo de atuação restrito às decisões inerentes a tarefas específicas.

Um trecho de uma entrevista na SPU/B esclarece a visão naquela superintendência:

Então, no caso específico, eu acho que o grande problema do Patrimônio da União é essa falta de regimento. Vou mais longe, a gente não tem uma estrutura séria, bem definida, você tem uma [...] e que, portanto deveriam ter uma estrutura "igual" que permitisse você fazer uma qualificação dos serviços de todas elas. Você poder julgá-las de forma equânime, até mesmo porque você tem servidores em todas essas superintendências, e [para] você avaliar esses servidores, você tem que ser justo nessa [avaliação].

Por fim, na última questão das Práxis - e das entrevistas, foi perguntado aos Praticantes: quais ações locais se destacam entre as que mais contribuíram para a consecução dos resultados de crescimento da arrecadação patrimonial? Os temas mais enfatizados foram:

SPU/A: O exercício do controle.

SPU/B: A atualização do cadastro.

SPU/C: A atualização do cadastro e a realização de transferências.

Uma declaração obtida na SPU/A ilustra bem o destaque dado à atualização cadastral:

Então, a atualização da planta, o recadastramento que você possa fazer, mesmo que em quantidade pequena, mas é muito importante. Essas são algumas ações locais que eu destaco: as transferências rápidas, o recadastramento de dois municípios, dos nossos três municípios que têm praias. Dois já foram recadastrados. Então, eu acho que essas são as ações locais que devem dar resultado para qualquer superintendência. 


\subsection{Análise dos documentos}

A despeito das características dos relatórios de gestão inviabilizarem a aplicação da análise de conteúdo sob os mesmos temas levantados nas entrevistas, as evidências obtidas naqueles corroboraram a visão dos Praticantes em seus pontos principais: quanto às restrições estruturais, aos aspectos contextuais e às atividades desempenhadas. Ademais, por serem documentos padronizados, não foram encontradas informações significativas que diferenciassem as três superintendências. Dessa forma, os relatórios de gestão 2010 foram analisados em conjunto, como Região Sul, cujos elementos de destaque estão apresentados no Quadro 1.

Quadro 1 - Elementos de destaque nos relatórios de gestão 2010 da Região Sul.

\section{Elementos de destaque nos relatórios de gestão 2010 da Região Sul}

1. É elaborado, em grande parte, com reprodução de informações padronizadas do órgão central

2. É produzido com ênfase nas informações quantitativas como prestação de contas

3. A apuração da GIAPU é um instrumento de gestão concorrente ao PPA

4. A metodologia empregada na GIAPU é diversa da utilizada no PPA, a despeito de utilizar o mesmo indicador (a arrecadação patrimonial)

5. Diferentemente do PPA, a GIAPU tem repercussão na remuneração dos servidores

6. Ações implementadas tem consequências que não se limitam ao exercício em curso, mas têm repercussões de longo prazo nas atividades cotidianas

7. Ocorre o registro das soluções contextuais implementadas, bem como a proposição e reivindicação de melhorias nas atividades e estruturas existentes

8. Os relatos sobre limitações na estrutura, deficiências no quadro colaborativo, bem como as precariedades na legislação, indicam que a eficácia e a eficiência do órgão ficam aquém do que poderiam apresentar

9. Devido às limitações na estrutura, recorre-se à realocação do esforço colaborativo e o uso de forças-tarefa como alternativas paliativas de contornar tais restrições, no entanto, outras atividades ficam acumulando em um passivo crescente 
A análise que conduziu aos elementos de destaque $n^{\circ} 3,4$ e 5 revelou uma constatação importante: os resultados de arrecadação não estavam sendo orientados pelas metas do PPA e sim, pelas metas da Gratificação de Incremento à Atividade de Administração do Patrimônio da União (GIAPU). Assim, a investigação foi conduzida aos relatórios de gestão da SPU de 2008, 2009 e 2010 em busca de mais evidências que subsidiassem essa observação. Especificamente em relação às metas de arrecadação estabelecidas para a GIAPU, foram encontrados valores diversos dos definidos para o PPA. A Tabela 3 apresenta comparativamente os valores.

Tabela 3 - Comparativo entre as metas da GIAPU e do PPA de 2008 a 2010.

\begin{tabular}{l|c|c|c|c|c}
\hline \multicolumn{2}{c}{ Comparativo entre as metas da GIAPU e do PPA de 2008 a 2010} \\
\hline Exercício & $\begin{array}{c}\text { Consolidado } \\
\text { (em milhões } \\
\text { de R\$) }\end{array}$ & $\begin{array}{c}\text { Consolidado } \\
\text { (superação } \\
\text { em relação à } \\
\text { meta GIAPU) }\end{array}$ & $\begin{array}{c}\text { Consolidado } \\
\text { (superação } \\
\text { em relação à } \\
\text { meta PPA) }\end{array}$ & $\begin{array}{c}\text { Meta GIAPU } \\
\text { (em milhões } \\
\text { de R\$) }\end{array}$ & $\begin{array}{c}\text { Meta } \\
\text { PPA (em } \\
\text { milhões de } \\
\text { R\$) }\end{array}$ \\
\hline 2010 & 635,94 & $42,98 \%$ & $77,40 \%$ & 444,77 & 358,47 \\
\hline 2009 & 459,23 & $5,01 \%$ & $37,39 \%$ & 437,32 & 334,25 \\
\hline 2008 & 437,32 & $3,50 \%$ & $41,05 \%$ & 422,53 & 310,03 \\
\hline
\end{tabular}

Não bastassem os valores divergentes entre as duas metas, observa-se, pelos percentuais que a meta da GIAPU foi superada com mais aproximação do que a do PPA (à exceção do atípico exercício de 2010). Por fim, a confirmação explícita da orientação pelas metas da GIAPU foi obtida mediante o seguinte trecho do relatório de gestão de 2010, da SPU, bem como explica o resultado atípico em 2010:

[...] Tem-se verificado sucessivo incremento nominal na arrecadação de R\$ 635,94 milhões, em 2010 (42,96\% acima da meta física estabelecida de $\mathrm{R} \$ 444,85$ milhões). Com relação ao ano de 2009, houve um crescimento de $38,48 \%$ na arrecadação. Cabe atentar que esse resultado tem influência da incorporação da Rede Ferroviária federal - RFFSA com uma arrecadação extraordinária de $\mathrm{R} \$ 73.759 .533,99$ ( $R$ \$ 71,5 milhões 
em outras receitas (cód. 2102) e R\$ 2,2 milhões em alienação de domínio pleno (cód. 4327)), sem o efeito estoque da RFFSA o valor arrecadado foi de $\mathrm{R} \$ 562,18$ milhões na arrecadação, um aumento de $26,38 \%$ com relação à meta física de $\mathrm{R} \$ 444,85$ milhões.

\section{Considerações finais}

Neste artigo, foram apresentados os resultados do estudo que analisou e comparou os diferentes Strategizings para o indicador TCAP do PPA 2008-2011, na visão da média gerência das três SPUs da Região Sul do Brasil. O referencial teórico adotado perpassou pela abordagem da ECP, que admite o desenvolvimento de estratégias sob o enfoque da prática socialmente contextualizada, bem como pela compreensão do PPA como plano estratégico para consecução dos objetivos governamentais. Para coleta dos dados primários, foram realizadas entrevistas semiestruturas com os superintendentes e os chefes das DIREPs e para coleta dos dados secundários realizou-se a pesquisa documental, que abrangeu os relatórios de gestão do órgão.

Foi verificado que os entrevistados, os Praticantes da estratégia, têm em comum, no mínimo, a formação acadêmica superior e já tinham experiência no setor público antes de assumirem seus encargos nas SPUs.

Relativo à visão da arrecadação patrimonial, no que tange à contribuição da mesma para o alcance dos objetivos do PPA, o entendimento na SPU/A é que esta pode contribuir para os programas sociais. Na SPU/B, ela não é importante para os objetivos do PPA. E na SPU/C discordou-se da SPU/B, afirmando que a arrecadação é importante para os objetivos do PPA, tem valor em si mesma e contribui positivamente para o órgão.

Quanto à definição do que é estratégia e do enfoque dado a esta na SPU/A, traduziu-se em atingir os objetivos mediante os recursos disponíveis (concepção analítica) e pelo aumento da eficiência (concepção adaptativa). Na SPU/B, o entendimento foi o de atingir os 
objetivos mediante o planejamento executivo (concepção prescritiva) e por meio de escolhas contextualizadas (concepção incrementalista). Por fim, na SPU/C, o conceito passa por atingir os objetivos mediante o conjunto de meios elaborados (concepção analítica), bem como pelo planejamento executivo (concepção prescritiva).

Concernente à visão sobre a implementação das estratégias, na SPU/A foi destacado que ter a estrutura adequada é um fator positivo. $\mathrm{Na}$ SPU/B, o destaque foi o aspecto negativo da arrogância da alta gerência. E a SPU/C citou como fator favorável o planejamento executivo.

No que diz respeito ao processo comunicativo, na SPU/A afirmase que inexiste interação, a despeito de ocorrer o retorno top-down. $\mathrm{Na}$ SPU/B, também, concordou-se com a SPU/A sobre a inexistência da interação. E na SPU/C foi destacada a transparência nos procedimentos.

A indagação sobre o processo decisório teve como resposta, na SPU/A, a necessária descentralização da tomada de decisões. $\mathrm{Na}$ SPU/B, foi ressaltada a desconsideração frente às restrições. Na SPU/C, declarou-se o aspecto negativo das decisões são do tipo top-down.

Como principais Práticas que mais contribuem para a arrecadação patrimonial, ficou notória a importância da atualização cadastral, uma vez que foi destacada pelas três superintendências, com o acréscimo da realização de transferências e da notificação direta, de forma exclusiva, pela SPU/C.

Quanto aos aspectos implementativos quando as Práticas são postas em execução, na SPU/A, foi enfatizado que se faz necessário o retorno down-top e que falhas ocorrem por falta de recursos. $\mathrm{Na}$ SPU/B, destacou-se que foi necessário o exercício do controle, bem como o incrementalismo e a inexistência de interação afetando de forma negativa. Na SPU/C, concordou-se com a SPU/B que se faz necessário o incrementalismo.

Relativo aos aspectos contextuais de como as Práticas afetam as atividades estratégicas cotidianas, na SPU/A, destacou-se que são fatores negativos a ausência de tempo hábil e se desconsiderar as 
restrições. Na SPU/B, a ênfase ficou na ocorrência de falhas por falta de estrutura. Na SPU/C, concordou-se com a SPU/A quanto à ausência de tempo hábil afetar de forma negativa.

Concernente à descrição de um modelo institucional, caso precisem incrementar a arrecadação, na SPU/A, enfatizou-se ser preciso estruturar do órgão. Na SPU/B, o destaque foi para serem necessárias comissões mistas entre os setores e a atualização do cadastro. $\mathrm{Na}$ SPU/C, concordou-se com a SPU/A que é preciso estruturar do órgão e, com a SPU/B, que é necessário a atualização do cadastro.

No que diz respeito à cultura organizacional quando novas Práticas se deparam com outras Práticas estratégicas já estabelecidas, na SPU/A, a ênfase foi na necessária flexibilidade, rapidez e priorização para a adaptação. Na SPU/B, destacou-se ser preciso uma gestão middle-up-down, bem como o exercício do controle. Já na SPU/C, a distinção ficou com o necessário engajamento do nível operacional.

Ao abordar as Práxis, sobre o porquê de as coisas serem feitas do jeito que são, na SPU/A, foi apontado o engajamento do nível operacional. $\mathrm{Na}$ SPU/B, enfatizou-se ser devido a uma cultura de descompromisso com a eficiência. Na SPU/C, acusou-se a estrutura ser determinística.

Relativo à forma local de fazer as coisas e a superintendência como instituição, na SPU/A, a ênfase recaiu sobre a autonomia ser somente operativa, à forte interação com o órgão central afetar positivamente, em contraponto às falhas no planejamento estratégico que afetam de forma negativa. Na SPU/B, concordou-se com a SPU/A quanto às falhas no planejamento estratégico afetarem negativamente. Porém, na SPU/C, os encontros regionais foram citados de forma positiva.

Concernente às ações locais que se destacam entre as que mais contribuíram para a consecução dos resultados de crescimento da arrecadação patrimonial, na SPU/A, foi apontado o exercício do controle. Na SPU/B, a ênfase recaiu sobre a atualização do cadastro, assim como na SPU/C. Já na SPU/B, quanto à realização de transferências. 
Pelo exposto, verifica-se que os Praticantes têm perfil profissional semelhante, tanto em relação à formação acadêmica, quanto concernente à experiência profissional no setor público. Na visão dos mesmos, não há unanimidade quanto à importância da arrecadação patrimonial para os objetivos do PPA, contudo, de certa forma, esta pode contribuir para o órgão e para os programas sociais. A concepção analítico-prescritiva é predominante no entendimento da estratégia, cuja implementação deve ser acompanhada do planejamento executivo e da necessária estrutura, a despeito de ser verificada arrogância por parte da alta gerência. A inexistência de interação é marcante no processo comunicativo, talvez em consequência de um processo decisório top-down, o que pode explicar as desconsiderações às restrições e, dessa forma, deseje-se a descentralização.

Quanto às Práticas, a média gerência foi unânime em destacar a atualização cadastral como contribuinte à arrecadação e, adicionalmente, enfatizaram que para implementá-las é preciso o incrementalismo, o controle, bem como os recursos e a interação down-top. Ademais, estas são afetadas negativamente pela ausência de tempo hábil, a inobservância das restrições e a falta de estrutura. Institucionalmente, a incrementação arrecadatória perpassaria pela estruturação do órgão e a atualização do cadastro, também já citados anteriormente. Sobre a cultura organizacional, houve o indicativo de uma necessária aproximação da gestão com o nível operacional.

No que diz respeito às Práxis, as coisas são realizadas como são por fatores diversos: seja pela estrutura determinística, seja pelo nível operacional se engajar, ou por uma cultura de descompromisso com a eficiência. No âmbito institucional, as Práxis são caracterizadas por falhas no planejamento estratégico, pela autonomia das superintendências serem somente operativas e favorecidas em encontros regionais e interação com o órgão central. Por fim, novamente, a atualização cadastral ficou destacada entre as ações que mais contribuíram para os resultados de arrecadação.

No encerramento das análises, o destaque ficou com os resultados advindos da pesquisa documental. Estes revelaram que, de fato, os 
resultados de arrecadação patrimonial estavam sendo orientados pelas metas da GIAPU e não pelas metas do PPA. Portanto, o indicador TCAP foi ignorado, não somente no desenvolvimento estratégico, como também considerado irrelevante nas tomadas de decisão do órgão. Resultado disso é se considerar o PPA uma peça meramente burocrática, cuja função principal é servir como instrumento de transparência aos órgãos de controle.

Relativamente à compreensão do Strategizing, o modelo composto pelos elementos Praticantes, Práticas e Práxis apresentou-se apropriado à compreensão e comparação de como se desenvolveu o processo estratégico nas três SPUs, em especial, por ter revelado a dinâmica das múltiplas interações entre os três fatores componentes da ECP, por ter se aprofundado na complexidade dos fatores que compuseram o âmbito da formulação-implementação, bem como por ter focado nas características micro e socialmente contextualizadas das estratégias nas organizações. Em suma, observou-se que a abordagem da ECP destacou o poder de agência dos Praticantes para o atingimento das metas pretendidas, conduzindo-se ao questionamento das concepções que enaltecem o aspecto prescritivo de conteúdo das estratégias.

Face ao exposto, as evidências possibilitam afirmar um modelo de gestão pública que comporte a abordagem da ECP, enfoque as micro-atividades socialmente contextualizadas, enfatize o processo interativo entre pessoas, ambiente, organização e a estratégia; que atue sob um planejamento estratégico mais próximo do nível operacional e acompanhado das estruturas fundamentais à implementação; que possa auxiliar o desenvolvimento e a implementação das estratégias de Governo pretendidas no planejamento plurianual das políticas públicas.

Para estudos futuros, propõe-se: realizar uma pesquisa longitudinal que permita investigar as micro-atividades estratégicas no longo prazo; desenvolver a investigação em outras superintendências, de forma a ampliar o número de casos pesquisados, dirimindo o viés regional; dar início a uma pesquisa survey nas demais superintendências a partir de temas observados nesse estudo; e a realização de uma pesquisa 
comparativa com outros órgãos do setor público, bem como do setor privado.

\section{Referências}

BARDIN, L. Análise de conteúdo. Lisboa: Edições 70, 2006.

BRASIL. Portaria $n^{\circ} 232$, de 3 de agosto de 2005. Anexo XII.

Regimento Interno da Secretaria do Patrimônio da União. Diário Oficial da União, Brasília, DF, v. 150, n. 60, p. 60-62, 5 ago. 2005.

. Ministério do Planejamento Orçamento e Gestão. Secretaria do Patrimônio da União. Estrutura organizacional. Disponível em: $<$ http://www.planejamento.gov.br/noticia.asp?p=not\&cod=344\&cat=73\& sec=9>. Acesso em: 30 jul. 2011.

. Ministério do Planejamento, Orçamento e Gestão. Secretaria de Planejamento e Investimentos Estratégicos. Plano plurianual 20082011: projeto de Lei. Brasília, DF, 2007.

CAVALCANTE, P. L. O Plano plurianual: resultados da mais recente reforma do planejamento e orçamento no Brasil. Revista do Serviço Público. Brasília, DF, v. 58, n. 2, p. 171-187, abr./jun. 2007.

CERTO, S. C. et al. Administração estratégica: planejamento e implantação da estratégia. 2. ed. São Paulo: Pearson Education do Brasil, 2005.

CHIZZOTTI, A. Pesquisa em ciências humanas e sociais. 8. ed. São Paulo: Cortez, 2006.

CURRIE, G.; PROCTER, S.; ORNE, H. The empowerment of middle managers in a community health trust: structure, responsibility and culture. Personnel Review, [s.I.], v. 28, n. 3, p. 242-257, 1999.

FENTON, C.; LANGLEY, A. Strategy as practice and the narrative turn. Organization Studies, Berlin, v. 32, n. 9, p. 1171-1197, 2011.

FLICK, U. Introdução à pesquisa qualitativa. 3. ed. Porto Alegre: Armed, 2009. 
FLOYD, Steven W.; WOOLDRIDGE, Bill. Middle management involvement in strategy and its associa- tion with strategy type: A research note. Strategic Management Journal, Chicago, v. 13, p. 153167, 1992.

FREEDMAN, M. The genius is in the implementation. Journal of Business Strategy, London, v. 24, n. 2, p. 26-31, Mar./Apr., 2003. HAMBRICK, D. C.; CANELLA, A. Strategy implementation as substance and selling. The Academy of Management Executive, Briarcliff Manor, v. 3, n. 4, p. 278-285, 1989.

HREBINIAK, L. G.; JOYCE, W. F. Implemenring strategy: appraisal and agenda for future research. In: HITT, M.; FREEMAN, R. E.; HARRISSON, J. S. (Ed.). The blackwell handbook of strategic management. 2nd ed. New York: J. Wiley, 2005. p. 602-626.

JARZABKOWSKI, P. Strategy as practice: an activity-based approach. London: Sage, 2005.

; BALOGUN, J.; SEIDL, D. Strategizing: the challenges of a practice perspective. Human Relations, London, v. 60, n. 1, p. 5-27, 2007.

; WILSON, David C. Actionable strategy knowledge: A practice perspective. European Management Journal, Glasgow, v. 24, n. 5, p. 348-367, 2006.

JOHNSON, Gerry; MELIN, Leif; WHITTINGTON, Richard. Microstrategy and strategizing: towards an activity-based view. Journal of Management Studies, Durham, v. 40, n. 1, p. 3-22, 2003.

KAPLAN, R. S.; NORTON, D. P. A organização orientada para a estratégia. Rio de Janeiro: Campus, 2001.

MARSHALL, C.; ROSSMAN, G. Designing qualitative research. Thousand Oaks: Sage, 1995.

MINAYO, M. C. S. (Org.). Pesquisa social: teoria, método e criatividade. Rio de Janeiro: Vozes, 2001. 
MINTZBERG, H.; AHLSTRAND, B.; LAMPEL, J. Safári de estratégia: um roteiro pela selva do planejamento estratégico. Porto Alegre:

Bookman, 2000.

NICHOL, Ronald L. Get middle managers involved in the planning process. Journal of Business Strategy, London, v. 13, n. 3, p. 26-32, 1992.

NORDBLOM, C. Involving middle managers in strategy at Volvo Group. London: Melcrum, 2006.

PARES, A.; VALLE, B. A retomada do planejamento governamental no Brasil e seus desafios. In: GIACOMONI, J.; PAGNUSSAT, J. L. (Org.). Planejamento e orçamento governamental. coletânea. Brasília, DF: ENAP, 2006. v. 1, p. 229-270.

PAULO, L. F. A. O PPA como instrumento de planejamento e gestão estratégica. Revista do Serviço Público. Brasília, DF, v. 2, n. 61, p. 171187, abr./jun. 2010.

PETERS, T. J.; WATERMAN, R. In search of excellence. New York: Harper \& Row, 1988.

REMENYI, D. et al. Doing research in business and management: an introduction to process and method. London: Sage, 2005.

SAUNDERS, M. N. K.; LEWIS, P.; THORNHILL, A. Research methods for business students. $5^{\text {th }}$. ed. Harlow: Financial Times Prentice Hall, 2009.

SEIDL, D. General strategy concepts and the ecology of strategy discourses: a systemic-discursive perspective. Organization Studies, Berlin, v. 28, n. 2, p. 197-218, 2011.

$\mathrm{SHAH}, \mathrm{A}$. M. The foundations of successful strategy implementation: overcoming the obstacles. Global Business Review, New Deli, v. 6, n. 2, p. 293-302, 2005.

SPEE, A. P.; JARZABKOWSKI, P. Strategic planning as a communicative process. Organization Studies, London, v. 32, n. 9, p. 1217-1246, 2011. 
WHITTINGTON, R. Completing the practice turn in strategy research. Organization Studies, Oxford, v. 27, n. 5, p. 613-634, 2006.

. Estratégia após o modernismo: recuperando a prática. $R A E$

- Revista de Administração de Empresas, São Paulo, v. 44, n. 4, p. 4453, out./dez. 2004.

. The work of strategizing and organizing: for a practice perspective. Strategic Organization, Oxford, v. 1, n. 1, p. 117-125, 2003.

; JOHNSON, G.; MELIN, L. The emerging field of strategy practice: some links, a trap, a choice and a confusion. In: EGOS Colloquium, 2004, Ljubljana. Anais... Ljubljana, Slovenia: EGOS, 2004. WHITTINGTON, R. et al. Strategy as practice: research directions and resources. New York: Cambridge University Press, 2007.

YIN, R. K. Estudo de caso: planejamento e métodos. 3. ed. Porto Alegre: Bookman, 2005. 